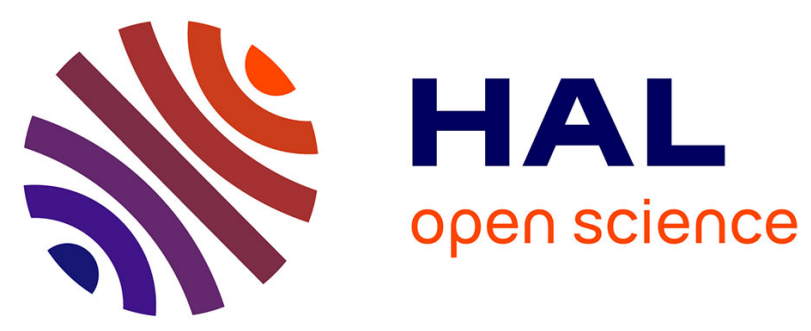

\title{
Incidence and risk factors of caesarean section in preterm breech births: A population-based cohort study
}

Elsa Lorthe, Mathilde Quere, Loïc Sentilhes, Pierre Delorme, Gilles Kayem

\section{To cite this version:}

Elsa Lorthe, Mathilde Quere, Loïc Sentilhes, Pierre Delorme, Gilles Kayem. Incidence and risk factors of caesarean section in preterm breech births: A population-based cohort study. European Journal of Obstetrics \& Gynecology and Reproductive Biology, 2017, 212, pp.37-43. 10.1016/j.ejogrb.2017.03.019 . hal-01688583

\section{HAL Id: hal-01688583 \\ https://hal.sorbonne-universite.fr/hal-01688583}

Submitted on 19 Jan 2018

HAL is a multi-disciplinary open access archive for the deposit and dissemination of scientific research documents, whether they are published or not. The documents may come from teaching and research institutions in France or abroad, or from public or private research centers.
L'archive ouverte pluridisciplinaire HAL, est destinée au dépôt et à la diffusion de documents scientifiques de niveau recherche, publiés ou non, émanant des établissements d'enseignement et de recherche français ou étrangers, des laboratoires publics ou privés. 
Incidence and risk factors of caesarean section in preterm breech births: a populationbased cohort study

3

4 Elsa Lorthe, ${ }^{1,2}$ RM, MSc, Mathilde Quere, ${ }^{1}$ MSc, Loïc Sentilhes, ${ }^{3}$ MD, PhD, Pierre 5 Delorme, ${ }^{1,4}$ MD, Gilles Kayem, ${ }^{1,2,5}$ MD, PhD

${ }^{1}$ Inserm Unité Mixte de Recherche 1153, Obstetrical, Perinatal and Pediatric Epidemiology Research Team (Epopé), Center for Epidemiology and Statistics Sorbonne Paris Cité, Département Hospitalo-Universitaire Risks in pregnancy, Paris Descartes University

${ }^{2}$ Sorbonne Universités, Université Pierre \& Marie Curie, Institut de Formation Doctorale, Paris, France

${ }^{3}$ Department of Obstetrics and Gynecology, Bordeaux University Hospital, Bordeaux, France

${ }^{4}$ Department of Obstetrics and Gynecology, Cochin, Broca, Hôtel Dieu Hospital, Assistance Publique Hôpitaux de Paris (AP-HP), Paris, France

${ }^{5}$ Department of Obstetrics and Gynecology, Trousseau Hospital, AP-HP, Paris, France

Corresponding author: Elsa Lorthe, INSERM U1153, Bâtiment Recherche, Hôpital Tenon, Email: elsa.lorthe@gmail.com

Disclosure of interest: The authors have no conflict of interest to report in relation with this article. 
31 Condensation: Breech presentation is common in preterm infants and is associated with

32 widespread use of cesarean delivery despite the absence of recommendations for mode of 33 delivery.

34

35

36

37

38

39

40

41

42

43

44

45

46

47

48

49 
Objectives: To describe the incidence of breech presentation at 22 to 34 weeks' gestation, estimate the incidence of cesarean section delivery by cause of prematurity, and assess the factors associated with caesarean delivery in preterm breech births with preterm labor or preterm premature rupture of membranes.

Study design: EPIPAGE 2 is a French national prospective population-based cohort study of preterm births that occurred in 546 maternity units in 2011. We estimated the overall incidence of breech presentation and the incidence of cesarean delivery by cause of prematurity. Among the 579 singletons with breech presentation born at 22 to 34 weeks in a context of spontaneous preterm labor or membrane rupture, multivariable logistic regression was used to assess the association between individual and institutional characteristics and caesarean delivery.

Results: Among the 3,660 singletons born at 22 to 34 weeks' gestation in the EPIPAGE 2 study, 20.1\% $(n=911)$ were breech presentation. Among these births, the rate of cesarean section was $99.6 \%$ with vascular pathologies, intrauterine growth retardation or placental abruption as compared with $60.1 \%$ with spontaneous preterm labor or membrane rupture. The main indication for caesarean delivery was gestational age associated with breech presentation $(61.0 \%)$. Delivery mode varied by region of birth. Other characteristics associated with caesarean delivery were hospital status (public teaching, public non-teaching or private), clinical chorioamniotitis, hospital admission after labor onset, and gestational age.

Conclusion: Breech presentation is common in preterm infants and is associated with widespread use of cesarean delivery with significant regional disparities that could reflect the lack of consensus and recommendations on the preferential mode of delivery. Other factors 
73 associated with caesarean delivery are the status of the maternity unit, clinical 74 chorioamniotitis, admission after labor onset and gestational age.

75

76 Keywords: EPIPAGE 2, breech presentation, preterm birth, mode of delivery, caesarean

77 section

78

79

80

81

82

83

84

85

86

87

88

89

90

91 


\section{Introduction}

Mode of delivery of preterm fetuses with breech presentation remains controversial (1-5). Obstetricians are often faced with this situation because the prevalence of the breech presentation is elevated with low gestational age: from $3 \%$ to $4 \%$ at term to $28 \%$ at 25 to 28 weeks' gestation $(6,7)$. This issue is crucial in obstetrical management. Indeed, the condition of the child, already exposed to the specific risks of prematurity, can worsen because of the potential complications associated with labor and vaginal delivery (anoxia, obstetric trauma, head entrapment, death) (8-10). In addition, caesarean section, which is technically difficult because of the absent or thicker lower uterine segment, is associated with non-negligible maternal risks both in the short term (2,11-13) and long term (14).

Results of a randomized controlled trial published in 2000 (15), concluded that the risk of neonatal death with term breech presentation was reduced with planned caesarean delivery as compared with planned vaginal delivery. This study included 2,183 women from 121 maternity units and 26 countries. Nevertheless, external validity was limited because of the large variation in local policies and individual skills and by the analysis of neonatal deaths unrelated to delivery route (16-18). These results largely contributed to changes in practices (19), with a greater use of caesarean delivery with breech presentation, at term but also before term, although the study did not provide any specific information concerning preterm breech presentation. Because of this lack of evidence, the National College of French Gynecologists and Obstetricians (CNGOF), in its guidelines of 1998 and 2016, does not recommend one delivery mode over another for preterm breech presentation (20-22).

The objectives of this work were to (1) describe the incidence of breech presentation in deliveries between 22 and 34 weeks' gestation, (2) estimate the incidence of caesarean section 
delivery with preterm breech presentation by cause of prematurity and (3) study the individual and institutional factors associated with caesarean delivery in preterm breech fetuses.

\section{Methods}

\section{Setting and data collection}

This study is based on data from the EPIPAGE2 (Etude épidémiologique sur les petits âges gestationnels) cohort study (23), a prospective, national, population-based cohort study implemented to describe the short- and long-term outcomes of preterm infants in terms of birth circumstances, medical practices and organization of care. Infants were included from March to December 2011 in 546 maternity units, representing 98\% of French maternity units. Infants born at 22 to 26 weeks, 27 to 31 weeks, and 32 to 34 weeks were included for 8 months, 6 months and 5 weeks, respectively. Different stages of follow-up are planned up to age 12 years. Individual perinatal data were collected from medical records in both maternity and neonatology units. The data for centers were obtained from a specific questionnaire sent to obstetrics and neonatology departments that included at least one live birth in the cohort (i.e., 413 centers).

\section{Participants}

Among the 7,804 infants born at 22 to 34 weeks' gestation included in the EPIPAGE2 study, we included all singletons who were alive at the beginning of labor or during the caesarean section performed before labor, who were in breech presentation. Exclusion criteria were multiple pregnancies, home births, terminations of pregnancy and stillbirths before labor. Because the use of caesarean section delivery is almost systematic in situations of prematurity induced for a maternal indication (e.g., hypertensive pathology) and/or fetal indication (e.g., intrauterine growth retardation [IUGR]), we focused on cases of spontaneous preterm labor 
(SPL) and preterm premature rupture of membranes (PPROM), these two case groups being mutually exclusive.

\section{Outcome and other studied factors}

141 The primary outcome was caesarean section delivery, performed before or during labor, as 142 reported in the medical record.

143 The variables analyzed first focused on maternity unit characteristics: region, type (type I: 144 without neonatal department; types IIa \& IIb: with neonatal department; type III: with 145 neonatal intensive care unit) and status of the institution (public teaching, public non-teaching 146 or private). We then studied maternal characteristics (age, nationality, employment, marital 147 status, parity, previous caesarean section) and obstetric characteristics (cause of preterm birth, 148 antenatal steroids, in utero transfer, clinical chorioamniotitis, admission after labor onset, 149 gestational age).

SPL was defined as preterm labor with intact membranes and PPROM as membranes ruptured more than $24 \mathrm{hr}$ before delivery. Gestational age was determined from a first trimester ultrasound or the date of the last menstrual period. Antenatal steroids use was a binary variable classified as at least one injection versus no injection of betamethasone or dexamethasone before delivery.

\section{Statistical analysis}

We first estimated the incidence of breech presentation by gestational age and that of 157 caesarean section by cause of prematurity. We then described the respective frequencies of 158 vaginal and caesarean deliveries and compared institutional and individual characteristics by mode of delivery. To account for the inclusion scheme of the study and for representative preterm births in France, a weighted coefficient was allocated to each individual (1 for births 
between 22 and 26 weeks, 1,346 for births between 27 and 31 weeks, and 7 for births between 32 and 34 weeks). The association between maternal or obstetric characteristics and caesarean section was estimated by univariate and multivariate logistic regression models and quantified by crude odds ratios (ORs) and adjusted ORs (aOR) and their confidence intervals (95\% CIs). The variables included in the multivariate model were chosen according to their clinical relevance. Data were missing for $0 \%$ to $9.5 \%$ of patients for each covariate. A missing data indicator class was added to each relevant categorical variable in the multivariate analysis. The adjustment of the multivariate model to the data was tested by the Hosmer-Lemeshow test; its discriminating power was evaluated by the area under the receiver operating characteristic curve. Data were analyzed by using Stata/SE 13.0 (StataCorp LP, College Station, TX). Statistical significance was set at 2-tailed $\mathrm{p}<.05$.

\section{Results}

\section{Incidence of breech presentation}

Among the 3,660 singletons born at 22 to 34 weeks included in the EPIPAGE 2 study, 911 (weighted percentage 20.1\%) were in breech presentation (Figure 1). The overall frequency of breech presentation varied by gestational age at birth: $47.1 \%$ to $37.4 \%$ at 22 to 26 weeks, $29.5 \%$ to $24.2 \%$ at 27 to 29 weeks, and $20.5 \%$ to $12.5 \%$ at 30 to 34 weeks (Figure 2).

\section{Incidence of caesarean section delivery with breech presentation by cause of prematurity}

The main causes of premature birth, mutually exclusive, were SPL (41.1\%), PPROM $(28.1 \%)$, vascular or hypertensive pathology $(22.1 \%)$, IUGR $(5.6 \%)$ or placental abruption $(3.1 \%)$. With breech presentation, caesarean delivery was almost systematic with vascular pathologies, IUGR and placental abruption (99.6\% of patients). It was performed for $60.1 \%$ of 
patients (95\% CI [54.6-65.7]) with breech presentation and SPL or PPROM with variations by week of gestational age (Figures 1, 2).

\section{Factors associated with caesarean delivery with breech presentation and SPL or PPROM}

The births included in this analysis occurred in 170 maternity units. Regional disparities existed: in Rhône-Alpes, Auvergne, Martinique and Limousin districts, more than $80 \%$ of births were caesarean deliveries as compared with less than $33 \%$ in French Guiana, Picardie, Centre and Haute-Normandie (Figure 3). Nearly one-third of births occurred in other than type III maternity units (Table 2). Before 32 weeks, $4.2 \%, 7.8 \%$ and $6.2 \%$ of infants were born in type I, IIa or IIb maternity units, respectively. Most deliveries occurred in a public institution: a public teaching hospital for $49.6 \%$ or a public non-teaching hospital for $41.5 \%$. After adjustment, region $(\mathrm{p}<.001)$ and hospital status $(\mathrm{p}=.005)$ were significantly associated with caesarean delivery (Tables 1,2$)$.

Among socio-demographic characteristics, the age of the mother and her nationality were not associated with the mode of delivery. However, single patients or housewives less often had a caesarean section delivery than patients in a couple relation or who were employed, respectively. These associations disappeared after adjusting for confounding factors (Table 2).

In terms of obstetrics history, nearly half of the mothers were multiparous; in total, $7.1 \%$ had a scarred uterus and $3.3 \%$ had had two or more previous caesarean sections. Parity was not associated with caesarean delivery. There was a gradient with an increase in caesarean deliveries by number of previous caesarean sections. This association was not found on multivariate analysis.

Concerning the current pregnancy, the cause of preterm birth, in utero transfer and antenatal corticosteroids were not associated with the delivery mode (Table 2). After adjustment, risk of 
caesarean delivery was increased with clinical chorioamniotitis (aOR 2.0 [1.1-3.7]) but reduced with admission after labor onset, representing $25.2 \%$ of patients, as compared with labor occurring during hospitalization (aOR 0.3 [0.1-0.5]).

Finally, risk of caesarean delivery was strongly associated with gestational age $(\mathrm{p}<.001)$, even after adjusting for individual and institutional characteristics (Table 2). No caesarean section was performed at 22 and 23 weeks' gestation (Figure 2). From 24 to 25 weeks, 1 in 5 patients had a caesarean section delivery. From 26 to 34 weeks, the frequency of caesarean delivery varied from $59.8 \%$ to $80.0 \%$. Gestational age associated with breech presentation was the main indication for caesarean section, reported in $61.0 \%$ of cases. Other non-mutually exclusive indications were maternal pathology (18.6\%), abnormal fetal heart rate before or during labor (18.3\%), fetal pathology (14.3\%) and/or stagnated dilation (1.7\%).

\section{Comment}

\section{Main findings}

Among singletons born at 22 to 34 weeks, $20.1 \%$ were breech presentations, with significant variations depending on gestational age. Most of these preterm deliveries were caesarean sections, 99.6\% with vascular pathologies, IUGR or placental abruption as compared with $60.1 \%$ with SPL or PPROM. Delivery mode appeared to vary by region of birth in France. Childbirth occurred in other than a type III maternity unit for nearly $20 \%$ of births before 32 weeks. Other characteristics associated with caesarean deliveries with preterm breech presentation were the status of the maternity unit, clinical chorioamniotitis, admission after labor onset, and gestational age.

\section{Strengths and limitations}


The main strength of this study is related to the design of the EPIPAGE2 cohort, a large national, prospective, population-based study. The strong involvement of families (93\% participation among all eligible children) and the systematic and standardized collection of precise individual data ensure good representation of patients and medical practices.

However, this analysis has some limitations. Indeed, 596 eligible children (7.1\%) were not included in the EPIPAGE 2 cohort because of parental refusal. Among these, 109 singletons (19.6\% [15.2-24.9]) were breech presentations, with no significant difference from children included in our analysis (data not shown). The comparison of caesarean delivery rates was not possible between these two groups because the cause of delivery was unknown with refusal of participation. However, non-participation is not likely linked to fetal presentation or mode of delivery, which limits this potential bias.

The missing data for the variables "presentation" and "cause of prematurity" led us to exclude 173 then 75 subjects from the analysis (i.e., 6.8\% of the initial sample). Infants whose presentation was unknown were more often delivered by caesarean section $(86.5 \%$ [79.094.0]) and less often because of SPL or PPROM (46.0\% [34.4-57.5]) than was our study population. Thus, most of these participants were not eligible for our analysis. Among the 75 infants for whom the cause of prematurity was missing, 66.2\% (53.6-78.8) were delivered by caesarean section, so the distribution of delivery route did not differ from that for our analysis population.

A final limitation was the lack of precise data on the type of breech presentation, frank or complete. This clinically relevant information may affect the choice of delivery route, with a complete breech considered to have a poorer obstetric prognosis. However, in the context of preterm births, the type of breech is not as important in the decision as gestational age or the speed of labor. 
253

Our results show a high rate of caesarean section deliveries in preterm breech singletons in France. Several factors can explain this result. First, situations of induced preterm birth (because of vascular pathology, IUGR...), which have increased in frequency in recent years (24), strongly affect the overall incidence of caesarean deliveries. In cases of SPL and PPROM, clinical guidelines do not guide the practitioner's choice $(20,22)$. The lack of consensus in the literature (1-5) and the fear of potential severe complications of labor and delivery can also explain the preponderant use of caesarean delivery. Its use may also be a reflection of the medico-legal considerations in the management of obstetric situations considered at risk $(16,25)$.

Performing a caesarean section is a marker of active antenatal care of the unborn child, as are antenatal steroids or magnesium sulfate for neuroprotection (26). Therefore, gestational age logically plays a preponderant role in this decision (26). Thus, in our study, no caesarean section was performed before the resuscitation threshold considered in France in 2011 (24 weeks). Thereafter, caesarean sections are more easily offered to patients with fetal vital prognosis considered "acceptable" (27), which corresponds to increasingly low gestational age as a result of advances in neonatology.

We showed significant regional variations in the frequency of caesarean deliveries for preterm breech presentations with SPL or PPROM. This heterogeneity may reflect regional disparities in the active antenatal care proposed in the context of extreme prematurity. Regional variations may also be related to variations in patient characteristics but also to a different distribution of maternity unit types and status. This contrast can reflect the leadership of the regional university hospital, where practitioners of peripheral maternity clinics have often been trained. 
This variability in delivery practices is often reported between countries, maternity units and even obstetricians $(25,28-30)$. In a French survey of management for breech presentations in university hospitals, Michel et al. found mean of $73.8 \%$ (range $50.3 \%$ to $98.3 \%$ ) declared rates of caesarean section deliveries (28). The authors reported that obstetric practices were little affected by gestational age and that only 3 of 18 hospitals included gestational age in their decision protocol for delivery route.

Clinical chorioamnionitis was associated with an increase in caesarean deliveries. This finding is consistent in the literature: caesarean delivery allows for shortening the fetal exposure to infection, especially when women are not in labor (31).

Unexpected delivery is common in situations of spontaneous prematurity, with a large number of patients in labor admitted to hospital. Therefore, the breech presentation is often diagnosed shortly before delivery (32). The delivery route must be chosen quickly, unless the imminence of birth leaves no other choice than vaginal delivery. Our results are consistent with findings from a retrospective study of term breeches showing that the probability of a vaginal birth increases with cervical dilation at admission $\geq 5 \mathrm{~cm}$ (33). This finding raises the question of the technical skills required for vaginal delivery in preterm breech presentations, especially in a sudden obstetric context, that is, when vaginal delivery is accepted by the obstetric team only because performing a caesarean section is impossible. This situation, often marked by emergency, requires precise and adapted gestures by all professionals, including younger ones (34).

\section{Conclusion}

Breech presentation is frequent for infants born at 22 to 34 weeks' gestation. In this clinical situation, the rate of caesarean deliveries in France is high, with significant regional 
disparities that could reflect the lack of consensus and recommendations on the preferential mode of delivery. Other factors associated with caesarean delivery are the status of the maternity unit, clinical chorioamniotitis, admission after labor onset and gestational age. The impact of the delivery mode on neonatal outcomes needs to be addressed.

Acknowledgements: We are grateful to the participating children and their families and to all maternity and neonatal units in France. The authors thank Laura Smales for editorial assistance and acknowledge the collaborators of the EPIPAGE2 Obstetric Writing Group. EPIPAGE 2 was funded by the French Institute of Public Health Research/Institute of Public Health and its partners: the French Health Ministry, the National Institute of Health and Medical Research (INSERM), the National Institute of Cancer, and the National Solidarity Fund for Autonomy (CNSA); the National Research Agency through the French EQUIPEX program of investments for the future (reference ANR-11-EQPX-0038); and the PREMUP Foundation. The funders had no role in the study design, data collection and analysis, decision to publish, or preparation of the manuscript. 


\section{References}

1. Kayem G, Combaud V, Lorthe E, Haddad B, Descamps P, Marpeau L, et al. Mortality and morbidity in early preterm breech singletons: impact of a policy of planned vaginal delivery. Eur J Obstet Gynecol Reprod Biol. 2015 Sep;192:61-5.

2. Alfirevic Z, Milan SJ, Livio S. Caesarean section versus vaginal delivery for preterm birth in singletons. In: Cochrane Database of Systematic Reviews [Internet]. John Wiley \& Sons, Ltd; 2013 [cited 2015 Sep 9]. Available from: http://onlinelibrary.wiley.com/doi/10.1002/14651858.CD000078.pub3/abstract

3. Bergenhenegouwen LA, Meertens LJE, Schaaf J, Nijhuis JG, Mol BW, Kok M, et al. Vaginal delivery versus caesarean section in preterm breech delivery: a systematic review. Eur J Obstet Gynecol Reprod Biol. 2014 Jan;172:1-6.

4. Bergenhenegouwen L, Vlemmix F, Ensing S, Schaaf J, van der Post J, Abu-Hanna A, et al. Preterm Breech Presentation: A Comparison of Intended Vaginal and Intended Cesarean Delivery. Obstet Gynecol. 2015 Dec;126(6):1223-30.

5. Sentilhes L, Brun S, Lorthe E, Kayem G. Preterm Breech Presentation: A Comparison of Intended Vaginal and Intended Cesarean Delivery. Obstet Gynecol. 2016 Jun;127(6):1170.

6. Scheer K, Nubar J. Variation of fetal presentation with gestational age. Am J Obstet Gynecol. 1976 May 15;125(2):269-70.

7. Azria E, Kayem G, Langer B, Marchand-Martin L, Marret S, Fresson J, et al. Neonatal Mortality and Long-Term Outcome of Infants Born between 27 and 32 Weeks of Gestational Age in Breech Presentation: The EPIPAGE Cohort Study. PLOS ONE. 2016 Jan 8;11(1):e0145768.

8. Herbst A, Källén K. Influence of mode of delivery on neonatal mortality and morbidity in spontaneous preterm breech delivery. Eur J Obstet Gynecol Reprod Biol. 2007 $\mathrm{Jul} ; 133(1): 25-9$.

9. Langer B. L'accouchement de l'enfant de petit poids. EMC - Obstétrique. 2011 Jan;6(2):1-12.

10. Bruey N, Reinbold D, Creveuil C, Dreyfus M. Sièges prématurés avant 35 semaines d'aménorrhée : quelle influence de la voie d'accouchement sur l'état néonatal ? Gynécologie Obstétrique Fertil. 2015 Nov;43(11):699-704.

11. Reddy UM, Rice MM, Grobman WA, Bailit JL, Wapner RJ, Varner MW, et al. Serious maternal complications after early preterm delivery (24-33 weeks' gestation). Am J Obstet Gynecol. 2015 Oct;213(4):538.e1-538.e9.

12. van Ham MAPC, van Dongen PWJ, Mulder J. Maternal consequences of caesarean section. A retrospective study of intra-operative and postoperative maternal complications of caesarean section during a 10-year period. Eur J Obstet Gynecol Reprod Biol. 1997 Jul;74(1):1-6. 
13. Patterson LS, O'Connell CM, Baskett TF. Maternal and perinatal morbidity associated with classic and inverted T cesarean incisions. Obstet Gynecol. 2002 Oct;100(4):633-7.

14. Sciscione AC, Landon MB, Leveno KJ, Spong CY, MacPherson C, Varner MW, et al. Previous Preterm Cesarean Delivery and Risk of Subsequent Uterine Rupture: Obstet Gynecol. 2008 Mar;111(3):648-53.

15. Hannah ME, Hannah WJ, Hewson SA, Hodnett ED, Saigal S, Willan AR. Planned caesarean section versus planned vaginal birth for breech presentation at term: a randomised multicentre trial. The Lancet. 2000 Oct 21;356(9239):1375-83.

16. Glezerman M. Five years to the term breech trial: The rise and fall of a randomized controlled trial. Am J Obstet Gynecol. 2006 Jan;194(1):20-5.

17. Lawson GW. The Term Breech Trial Ten Years On: Primum Non Nocere? Birth. 2012 Mar 1;39(1):3-9.

18. Goffinet F, Carayol M, Foidart J-M, Alexander S, Uzan S, Subtil D, et al. Is planned vaginal delivery for breech presentation at term still an option? Results of an observational prospective survey in France and Belgium. Am J Obstet Gynecol. 2006 Apr;194(4):1002-11.

19. Hogle KL, Kilburn L, Hewson S, Gafni A, Wall R, Hannah ME. Impact of the international term breech trial on clinical practice and concerns: a survey of centre collaborators. J Obstet Gynaecol Can JOGC J Obstétrique Gynécologie Can JOGC. 2003 Jan;25(1):14-6.

20. CNGOF - RECOMMANDATIONS POUR LA PRATIQUE MEDICALE - Acct enfant faible poids [Internet]. [cited 2017 Jan 28]. Available from: http://www.cngof.asso.fr/D_PAGES/PURPC_04.HTM

21. Mottet N, Riethmuller D. Mode d'accouchement en cas de prématurité spontanée. Httpwwwem-Premiumcomdatarevues03682315unassignS0368231516301508 [Internet]. 2016 Oct 22 [cited 2016 Nov 22]; Available from: http://www.empremium.com/article/1090082/

22. Sentilhes L, Sénat M-V, Ancel P-Y, Azria E, Benoist G, Blanc J, et al. Prevention of spontaneous preterm birth: Guidelines for clinical practice from the French College of Gynaecologists and Obstetricians (CNGOF). Eur J Obstet Gynecol Reprod Biol. 2017 Mar;210:217-24.

23. Ancel P-Y, Goffinet F, EPIPAGE 2 Writing Group. EPIPAGE 2: a preterm birth cohort in France in 2011. BMC Pediatr. 2014;14:97.

24. Zeitlin J, Szamotulska K, Drewniak N, Mohangoo A, Chalmers J, Sakkeus L, et al. Preterm birth time trends in Europe: a study of 19 countries. Bjog. 2013 Oct;120(11):1356-65.

25. Penn ZJ, Steer PJ. How obstetricians manage the problem of preterm delivery with special reference to the preterm breech. Br J Obstet Gynaecol. 1991 Jun;98(6):531-4. 
26. Perlbarg J, Ancel PY, Khoshnood B, Durox M, Boileau P, Garel M, et al. Delivery room management of extremely preterm infants: the EPIPAGE-2 study. Arch Dis Child - Fetal Neonatal Ed. 2016 Sep 1;101(5):F384-90.

27. Eckman A, Mottet N, Ramanah R, Riethmuller D. Accouchement du prématuré. J Gynécologie Obstétrique Biol Reprod [Internet]. 2015 Jun [cited 2015 Aug 27]; Available from: http://linkinghub.elsevier.com/retrieve/pii/S0368231515001611

28. Michel S, Drain A, Closset E, Deruelle P, Subtil D. Évaluation des protocoles de décision de voie d'accouchement en cas de présentation du siège dans 19 CHU en France. J Gynécologie Obstétrique Biol Reprod. 2009 Sep;38(5):411-20.

29. Sharma JB, Newman MR, Boutchier JE, Williams A. National audit on the practice and training in breech deliveries in the United Kingdom1. Int J Gynecol Obstet. 1997 Nov 1;59(2):103-8.

30. Macfarlane A, Blondel B, Mohangoo A, Cuttini M, Nijhuis J, Novak Z, et al. Wide differences in mode of delivery within Europe: risk-stratified analyses of aggregated routine data from the Euro-Peristat study. BJOG Int J Obstet Gynaecol. 2016 Mar 1;123(4):559-68.

31. Son M, Grobman WA, Miller ES. Is mode of delivery associated with the risk of necrotizing enterocolitis? Am J Obstet Gynecol. 2016 Sep;215(3):389.e1-389.e4.

32. Leung WC, Pun TC, Wong WM. Undiagnosed breech revisited. Br J Obstet Gynaecol. 1999 Jul;106(7):638-41.

33. Faivre M, Mottet N, Bourtembourg A, Ramanah R, Maillet R, Riethmuller D. Pronostic obstétrical de la présentation du siège en cas d'admission en travail avancé. $\mathrm{J}$ Gynécologie Obstétrique Biol Reprod [Internet]. 2015 Jul [cited 2016 Apr 20]; Available from: http://linkinghub.elsevier.com/retrieve/pii/S0368231515001659

34. Queenan JT. Teaching Infrequently Used Skills: Vaginal Breech Delivery: Obstet Gynecol. 2004 Mar;103(3):405-6. 
430 Figure 1: Flow of participants in the study.

431 Figure 2: Incidence of breech presentation and rate of caesarean section by week of 432 gestational age.

433 Figure 3: Incidence of breech presentation and mode of delivery by region of birth.* Legend: * The Poitou-Charentes region did not participate.

435

436 Table 1: Association between the region of birth and caesarean section with breech 437 presentation and spontaneous preterm labor (SPL) or preterm premature rupture of 438 membranes (PPROM).

439 Table 2: Association between institutional and individual characteristics and caesarean section 440 with breech presentation and SPL or PPROM. 
Figure 1: Flow of infants in the study.

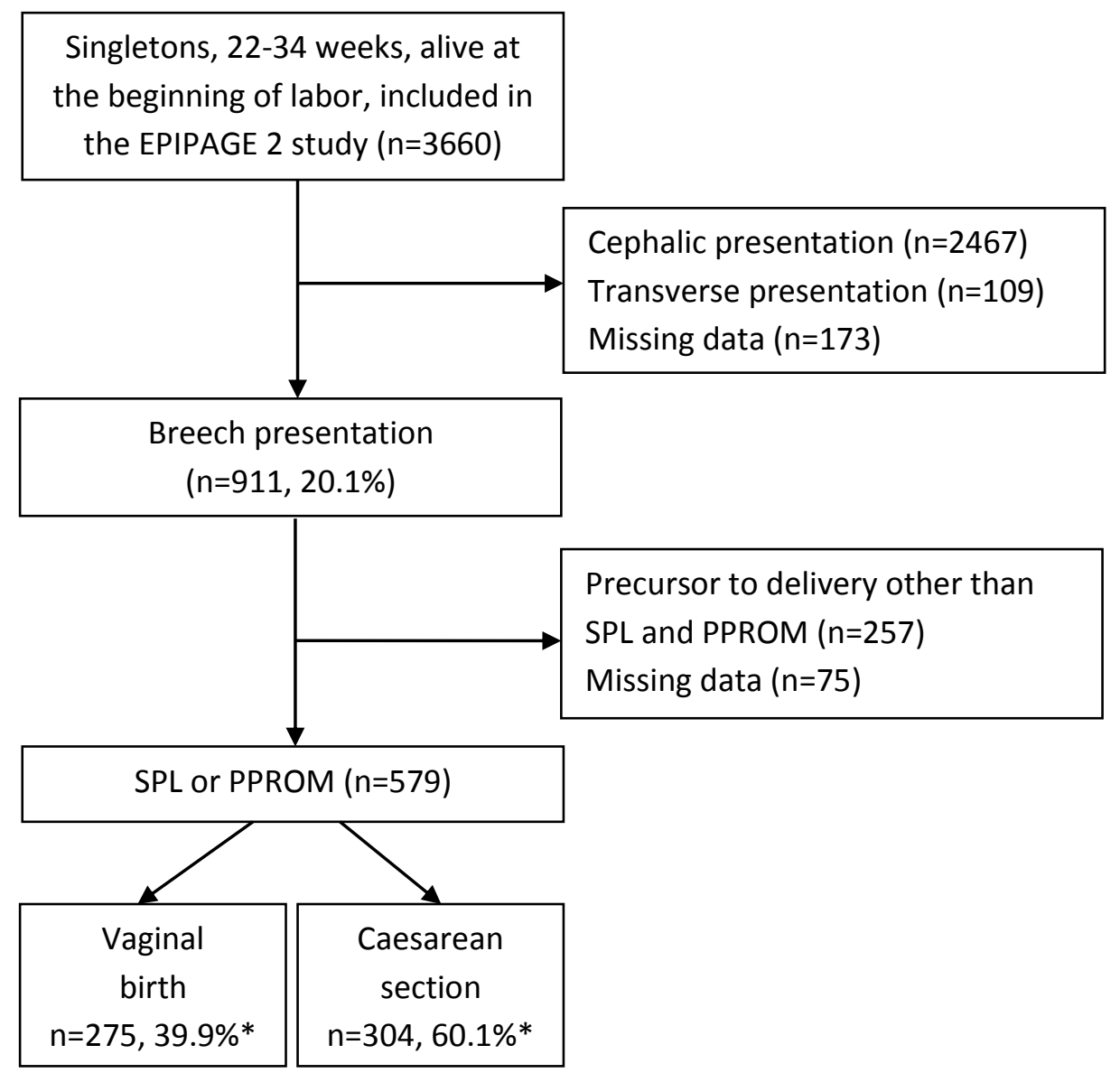

SPL: spontaneous preterm labor

PPROM: preterm premature rupture of membranes

* Percentages are weighted according to gestational age. 
Figure 2: Incidence of breech presentation* and rate of caesarean section by week of gestational age.

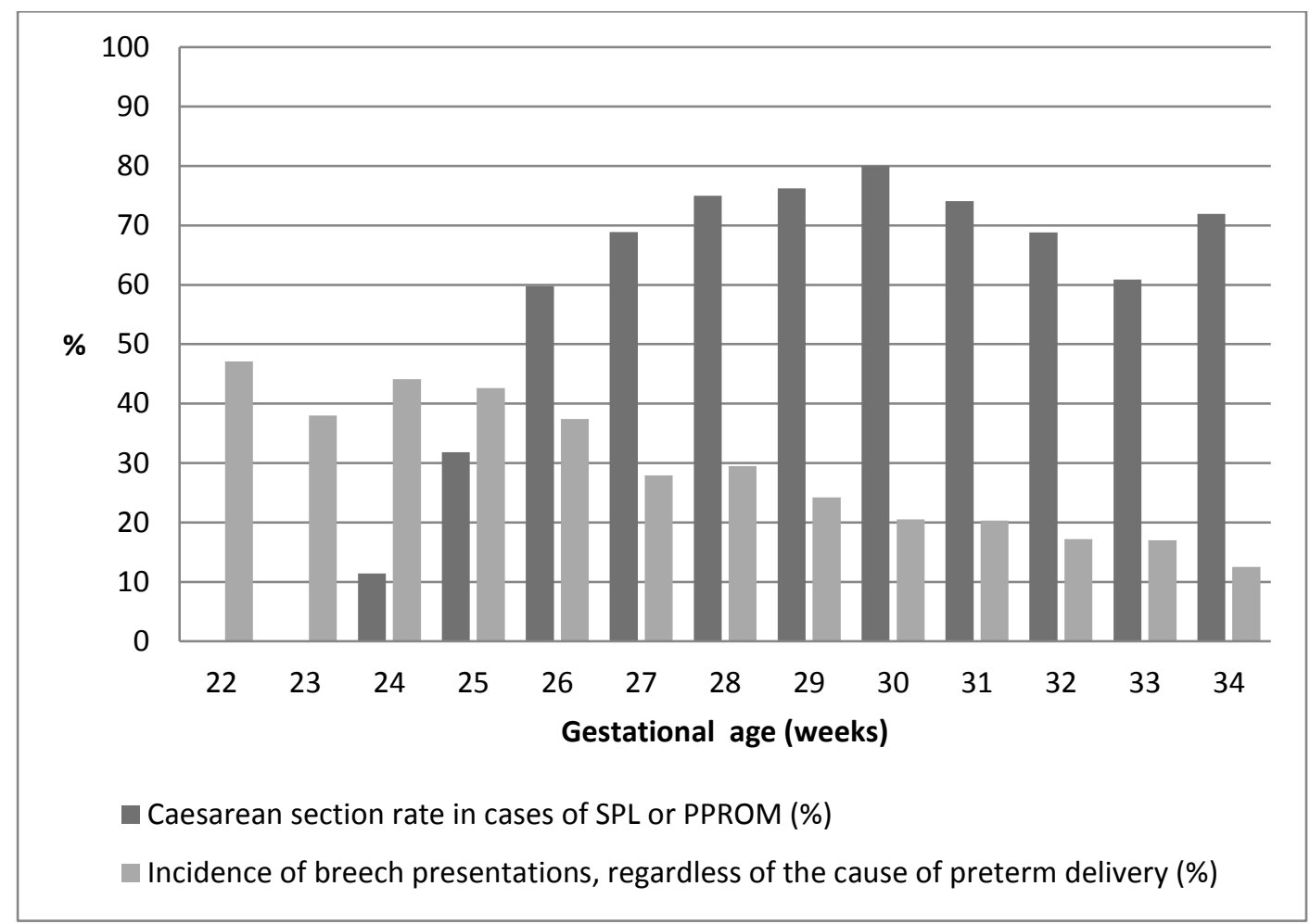

* The incidence of breech presentation is assessed among the 3487 singletons, born at 22 to 34 weeks, alive at the beginning of labor with information about fetal presentation. 

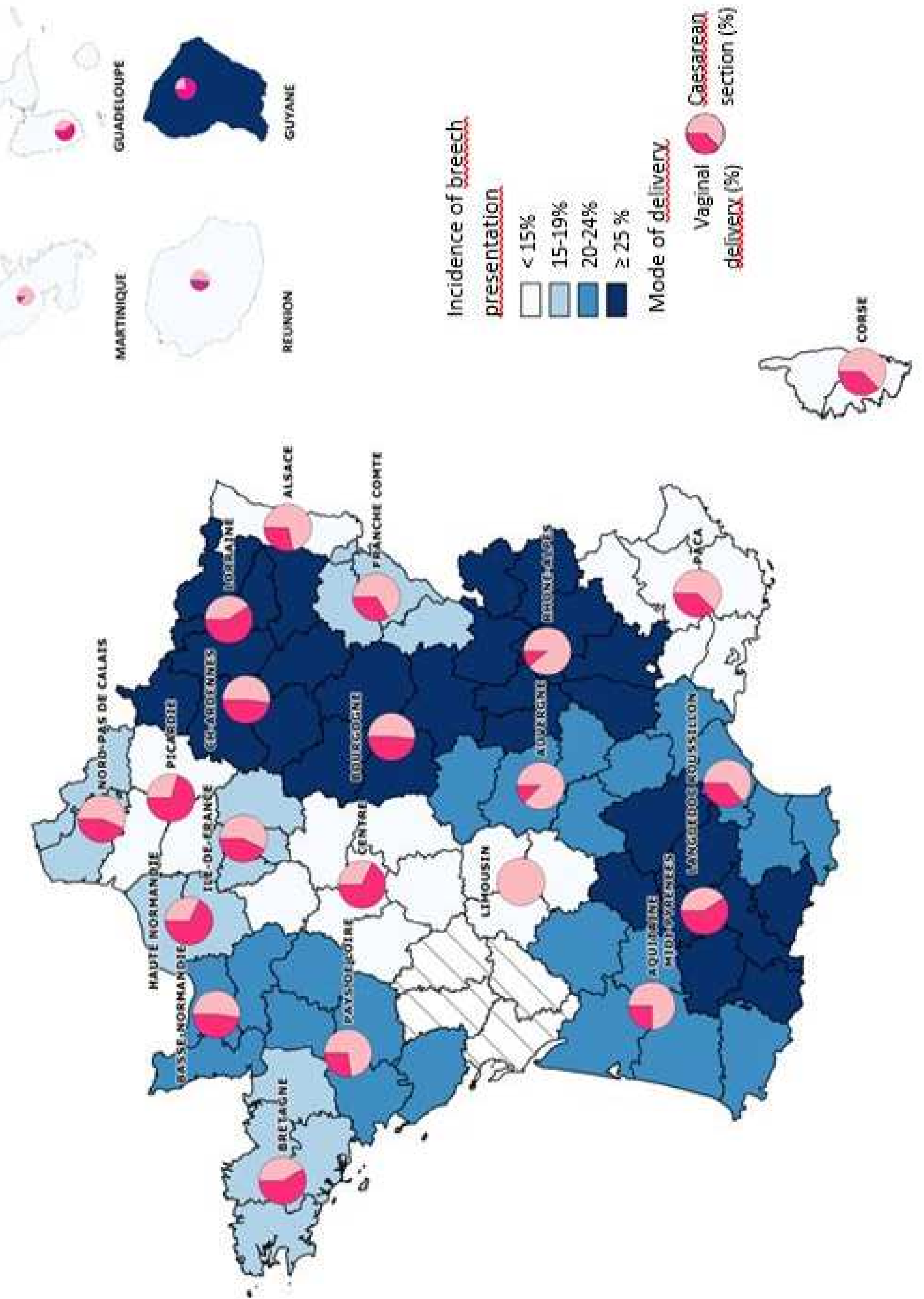
Table 1: Association between the region of birth and caesarean section with breech presentation and spontaneous preterm labor (SPL) or preterm premature rupture of membranes (PPROM).

\begin{tabular}{|c|c|c|c|c|}
\hline & $\begin{array}{l}\text { Vaginal birth } \\
(n=275)\end{array}$ & $\begin{array}{l}\text { Caesarean section } \\
(\mathrm{n}=304)\end{array}$ & Bivariate analysis & $\begin{array}{l}\text { Multivariate } \\
\text { analysis }\end{array}$ \\
\hline & $\mathrm{n}(\%)^{*}$ & $\mathrm{n}(\%)^{*}$ & OR* $(95 \% \mathrm{Cl})$ & $\mathrm{aOR}^{* *}(95 \% \mathrm{Cl})$ \\
\hline \multicolumn{5}{|l|}{ Region of birth } \\
\hline Alsace & $7(28.7)$ & $10(71.3)$ & $1.8(0.5-6.4)$ & $2.1(0.5-8.3)$ \\
\hline Aquitaine & $6(25.0)$ & $16(75.0)$ & $2.2(0.5-9.4)$ & $2.3(0.7-8.4)$ \\
\hline Auvergne & $2(12.7)$ & $6(87.3)$ & $5.1(0.8-31.7)$ & $2.9(0.4-22.3)$ \\
\hline Basse Normandie & $9(47.6)$ & $5(52.4)$ & $0.8(0.2-3.7)$ & $0.4(0.1-1.7)$ \\
\hline Bourgogne & $8(48.3)$ & $8(51.7)$ & $0.8(0.2-3.4)$ & $1.0(0.2-3.8)$ \\
\hline Bretagne & $14(58.4)$ & $9(41.6)$ & $0.5(0.2-1.4)$ & $0.6(0.2-2.2)$ \\
\hline Centre & $7(68.3)$ & $5(31.7)$ & $0.3(0.1-1.6)$ & $2.5(0.5-13.4)$ \\
\hline Champagne-Ardenne & $5(48.0)$ & $6(52.0)$ & $0.8(0.1-4.5)$ & $0.4(0.1-2.1)$ \\
\hline Franche-Comté & $3(33.8)$ & $6(66.2)$ & $1.5(0.2-10.0)$ & $5.6(0.7-44.8)$ \\
\hline Guadeloupe & $5(61.5)$ & $3(38.5)$ & $0.5(0.1-2.1)$ & $1.2(0.1-10.8)$ \\
\hline Guyane & $5(77.5)$ & $4(22.5)$ & $0.2(0.1-1.1)$ & $0.3(0.1-2.1)$ \\
\hline Haute Normandie & $10(67.5)$ & $7(32.5)$ & $0.4(0.1-1.2)$ & $0.7(0.2-2.7)$ \\
\hline Ile de France & $71(42.6)$ & $67(57.4)$ & 1 & 1 \\
\hline Languedoc Roussillon & $7(36.0)$ & $22(64.0)$ & $1.3(0.4-4.5)$ & $11.5(3.2-41.8)$ \\
\hline Limousin & $0(0.0)$ & $2(100.0)$ & - & - \\
\hline Lorraine & $13(59.5)$ & $5(40.5)$ & $0.5(0.1-2.2)$ & $0.6(0.2-2.4)$ \\
\hline Martinique & 1 (12.9) & $5(87.1)$ & $5.0(0.5-45.2)$ & $23.7(0.6-949.5)$ \\
\hline Midi-Pyrénées & $13(59.5)$ & $12(40.5)$ & $0.5(0.2-1.6)$ & $0.7(0.2-2.3)$ \\
\hline Nord Pas de Calais & $26(43.7)$ & $16(56.3)$ & $1.0(0.4-2.4)$ & $0.5(0.2-1.4)$ \\
\hline Provence Alpes Côte & $21(37.5)$ & $21(62.5)$ & $1.2(0.5-3.0)$ & $2.4(0.9-6.6)$ \\
\hline \multicolumn{5}{|l|}{ d'Azur } \\
\hline Pays de Loire & $15(27.3)$ & $19(72.7)$ & $2.0(0.8-5.0)$ & $3.2(1.1-9.5)$ \\
\hline Picardie & $5(70.3)$ & $2(29.7)$ & $0.3(0.1-1.7)$ & $0.3(0.1-2.2)$ \\
\hline Réunion & $8(48.2)$ & $3(51.8)$ & $0.8(0.1-4.5)$ & $1.5(0.3-8.1)$ \\
\hline Rhône-Alpes & $14(11.3)$ & $45(88.7)$ & $5.8(2.6-13.2)$ & $6.7(2.3-19.1)$ \\
\hline
\end{tabular}

* Percentages and odds ratios (ORs) are weighted according to gestational age.

** aOR: OR adjusted for region, type and status of maternity unit, age, nationality, employment, marital status, parity, scarred uterus, cause of preterm birth, antenatal steroids use, in utero transfer, clinical chorioamniotitis, admission after labor onset, gestational age $95 \% \mathrm{Cl}, 95 \%$ confidence interval 
Table 2: Association between institutional and individual characteristics and caesarean section with breech presentation and SPL or PPROM.

\begin{tabular}{|c|c|c|c|c|c|c|}
\hline & & $\begin{array}{l}\text { Total } \\
(n=579)\end{array}$ & $\begin{array}{l}\text { Vaginal birth } \\
(n=275)\end{array}$ & $\begin{array}{l}\text { Caesarean } \\
\text { section } \\
(n=304)\end{array}$ & $\begin{array}{l}\text { Bivariate } \\
\text { analysis }\end{array}$ & $\begin{array}{l}\text { Multivariate } \\
\text { analysis }\end{array}$ \\
\hline & & $\mathrm{n}(\%)^{*}$ & $\mathrm{n}(\%)^{*}$ & $\mathrm{n}(\%)^{*}$ & $\mathrm{OR}^{*}(95 \% \mathrm{Cl})$ & $\mathrm{aOR}^{* *}(95 \% \mathrm{Cl})$ \\
\hline \multicolumn{7}{|c|}{ Maternity unit characteristics } \\
\hline \multirow[t]{4}{*}{ Unit type } & 1 & $27(4.9)$ & $19(6.0)$ & $8(4.1)$ & $0.7(0.2-2.1)$ & $0.6(0.1-2.3)$ \\
\hline & Ila & $54(11.9)$ & $33(13.2)$ & $21(11.1)$ & $0.9(0.4-1.9)$ & $0.8(0.3-2.4)$ \\
\hline & IIb & $53(15.6)$ & $29(12.5)$ & $24(17.7)$ & $1.4(0.7-3.1)$ & $0.9(0.3-2.3)$ \\
\hline & III & $445(67.6)$ & $194(68.3)$ & $251(67.1)$ & 1 & 1 \\
\hline \multirow[t]{3}{*}{ Hospital status } & Public teaching & $315(49.6)$ & $146(53.8)$ & $169(46.8)$ & 1 & 1 \\
\hline & Public non-teaching & $213(41.5)$ & $100(39.4)$ & $113(42.9)$ & $1.2(0.8-2.0)$ & $3.3(1.7-6.2)$ \\
\hline & Private & $32(8.9)$ & $16(6.8)$ & $16(10.3)$ & $1.8(0.6-4.8)$ & $2.3(0.6-8.8)$ \\
\hline \multicolumn{7}{|c|}{ Maternal characteristics } \\
\hline \multirow[t]{3}{*}{ Age (years) } & $<20$ & $27(2.9)$ & $18(4.6)$ & $9(1.7)$ & $0.4(0.2-0.9)$ & $0.8(0.2-2.5)$ \\
\hline & $20-34$ & $440(76.5)$ & $215(78.2)$ & $225(75.4)$ & 1 & 1 \\
\hline & $\geq 35$ & $111(20.6)$ & $41(17.2)$ & 70 (22.9) & $1.4(0.7-2.6)$ & $1.3(0.7-2.4)$ \\
\hline \multirow[t]{2}{*}{ Nationality } & French & $446(85.1)$ & $206(82.0)$ & $240(87.1)$ & 1 & 1 \\
\hline & Other & 85 (14.9) & $46(18.0)$ & 39 (12.9) & $0.7(0.3-1.3)$ & $1.0(0.5-2.0)$ \\
\hline \multirow[t]{2}{*}{ Marital status } & Marital life & $482(91.5)$ & $223(86.1)$ & $259(95.0)$ & 1 & 1 \\
\hline & Single & $61(8.5)$ & 34 (13.9) & $27(5.0)$ & $0.3(0.2-0.6)$ & $0.8(0.4-1.8)$ \\
\hline \multirow[t]{3}{*}{ Employment } & Employed & $333(65.3)$ & $139(57.0)$ & $194(70.5)$ & 1 & 1 \\
\hline & Unemployed & $61(9.7)$ & $31(9.8)$ & $30(9.7)$ & $0.8(0.4-1.7)$ & $1.1(0.5-2.5)$ \\
\hline & Housewife & $143(25.0)$ & $79(33.2)$ & $64(19.8)$ & $0.5(0.3-0.8)$ & $0.8(0.4-1.5)$ \\
\hline \multicolumn{7}{|c|}{ Obstetric characteristics } \\
\hline \multirow[t]{3}{*}{ Parity } & 0 & $298(51.2)$ & $154(53.5)$ & $144(49.7)$ & 1 & 1 \\
\hline & 1 & $156(26.0)$ & $71(26.0)$ & 85 (25.9) & $1.1(0.6-1.9)$ & $0.7(0.4-1.3)$ \\
\hline & 2 or more & $124(22.8)$ & $49(20.5)$ & $75(24.4)$ & $1.3(0.7-2.4)$ & $0.8(0.4-1.7)$ \\
\hline \multirow[t]{3}{*}{ Scarred uterus } & No & $486(89.6)$ & $245(93.4)$ & 241 (86.9) & 1 & 1 \\
\hline & 1 previous scar & $46(7.1)$ & $15(5.4)$ & $31(8.3)$ & $1.6(0.7-3.9)$ & $1.9(0.8-4.8)$ \\
\hline & $\geq 2$ previous scars & $19(3.3)$ & $5(1.2)$ & $14(4.8)$ & $4.3(1.3-13.8)$ & $2.3(0.5-11.4)$ \\
\hline \multirow{2}{*}{$\begin{array}{l}\text { Cause of } \\
\text { preterm birth }\end{array}$} & SPL & 341 (59.1) & $184(62.0)$ & $157(57.2)$ & 1 & 1 \\
\hline & PPROM & 238 (40.9) & $91(38.0)$ & $147(42.8)$ & $1.2(0.8-2.0)$ & $1.2(0.7-2.0)$ \\
\hline \multirow{4}{*}{$\begin{array}{l}\text { Clinical } \\
\text { chorioamnionitis } \\
\text { In utero transfer }\end{array}$} & No & 387 (82.4) & $188(83.0)$ & 199 (81.9) & 1 & 1 \\
\hline & Yes & $139(17.6)$ & $59(17.0)$ & $80(18.1)$ & $1.1(0.7-1.8)$ & $2.0(1.1-3.7)$ \\
\hline & No & $326(59.8)$ & $186(65.7)$ & $140(56.0)$ & 1 & 1 \\
\hline & Yes & $247(40.2)$ & $84(34.3)$ & $163(44.0)$ & $1.5(0.9-2.5)$ & $1.6(0.9-2.7)$ \\
\hline \multirow{2}{*}{$\begin{array}{l}\text { Antenatal } \\
\text { steroids use }\end{array}$} & No & $182(33.0)$ & 128 (39.7) & $54(28.5)$ & 1 & 1 \\
\hline & Yes & $384(67.0)$ & $139(60.3)$ & $245(71.5)$ & $1.7(1.0-2.8)$ & $1.5(0.8-2.7)$ \\
\hline \multirow{2}{*}{$\begin{array}{l}\text { Admission after } \\
\text { labor onset }\end{array}$} & No & $417(74.8)$ & $169(63.2)$ & $248(82.7)$ & 1 & 1 \\
\hline & Yes & $148(25.2)$ & $102(36.8)$ & $46(17.3)$ & $0.4(0.2-0.6)$ & $0.3(0.1-0.5)$ \\
\hline \multirow{5}{*}{$\begin{array}{l}\text { Gestational age } \\
\text { (weeks) }\end{array}$} & $22-25$ & $187(17.2)$ & $159(36.7)$ & $28(4.3)$ & $0.1(0.0-0.2)$ & $0.1(0.0-0.2)$ \\
\hline & $26-27$ & $127(13.1)$ & 47 (11.9) & $80(13.8)$ & $0.8(0.4-1.5)$ & $0.8(0.4-1.7)$ \\
\hline & $28-29$ & $86(10.6)$ & $21(6.5)$ & $65(13.4)$ & $1.5(0.7-3.0)$ & $1.7(0.7-4.1)$ \\
\hline & $30-31$ & $108(13.4)$ & $25(7.8)$ & 83 (17.1) & $1.6(0.8-3.1)$ & $1.8(0.8-4.2)$ \\
\hline & $32-34$ & $71(45.7)$ & $23(37.1)$ & $48(51.4)$ & 1 & 1 \\
\hline
\end{tabular}

Hosmer-Lemeshow statistic $=0.08$, area under the receiver operating characteristic curve (AUC) $=0.88$ SPL: spontaneous preterm labor, PPROM: preterm premature rupture of membranes

* Percentages and ORs are weighted according to gestational age.

** aOR: OR adjusted for region, type and status of maternity unit, age, nationality, employment, marital status, parity, scarred uterus, cause of preterm birth, antenatal steroids use, in utero transfer, clinical chorioamniotitis, admission after labor onset, gestational age 